NASA/TM—2008-215449

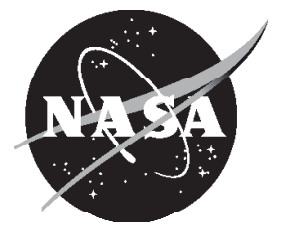

\title{
Advanced Stirling Convertor Heater Head Durability and Reliability Quantification
}

Ashwin R. Shah and Igor Korovaichuk

Sest, Inc., Middleburg Heights, Ohio

David L. Krause

Glenn Research Center, Cleveland, Ohio

Sreeramesh Kalluri

Ohio Aerospace Institute, Brook Park, Ohio 


\section{NASA STI Program . . . in Profile}

Since its founding, NASA has been dedicated to the advancement of aeronautics and space science. The NASA Scientific and Technical Information (STI) program plays a key part in helping NASA maintain this important role.

The NASA STI Program operates under the auspices of the Agency Chief Information Officer. It collects, organizes, provides for archiving, and disseminates NASA's STI. The NASA STI program provides access to the NASA Aeronautics and Space Database and its public interface, the NASA Technical Reports Server, thus providing one of the largest collections of aeronautical and space science STI in the world. Results are published in both non-NASA channels and by NASA in the NASA STI Report Series, which includes the following report types:

- TECHNICAL PUBLICATION. Reports of completed research or a major significant phase of research that present the results of NASA programs and include extensive data or theoretical analysis. Includes compilations of significant scientific and technical data and information deemed to be of continuing reference value. NASA counterpart of peer-reviewed formal professional papers but has less stringent limitations on manuscript length and extent of graphic presentations.

- TECHNICAL MEMORANDUM. Scientific and technical findings that are preliminary or of specialized interest, e.g., quick release reports, working papers, and bibliographies that contain minimal annotation. Does not contain extensive analysis.

- CONTRACTOR REPORT. Scientific and technical findings by NASA-sponsored contractors and grantees.

- CONFERENCE PUBLICATION. Collected papers from scientific and technical conferences, symposia, seminars, or other meetings sponsored or cosponsored by NASA.

- SPECIAL PUBLICATION. Scientific, technical, or historical information from NASA programs, projects, and missions, often concerned with subjects having substantial public interest.

- TECHNICAL TRANSLATION. Englishlanguage translations of foreign scientific and technical material pertinent to NASA's mission.

Specialized services also include creating custom thesauri, building customized databases, organizing and publishing research results.

For more information about the NASA STI program, see the following:

- Access the NASA STI program home page at http://www.sti.nasa.gov

- E-mail your question via the Internet to help@ sti.nasa.gov

- Fax your question to the NASA STI Help Desk at 301-621-0134

- Telephone the NASA STI Help Desk at 301-621-0390

- Write to: NASA Center for AeroSpace Information (CASI) 7115 Standard Drive Hanover, MD 21076-1320 
NASA/TM-2008-215449

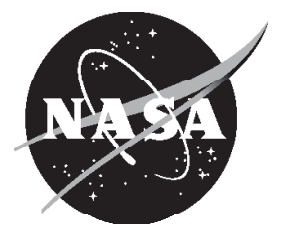

\section{Advanced Stirling Convertor Heater Head Durability and Reliability Quantification}

Ashwin R. Shah and Igor Korovaichuk

Sest, Inc., Middleburg Heights, Ohio

David L. Krause

Glenn Research Center, Cleveland, Ohio

Sreeramesh Kalluri

Ohio Aerospace Institute, Brook Park, Ohio

Prepared for the

Sixth International Energy Conversion Engineering Conference (IECEC)

sponsored by the American Institute of Aeronautics and Astronautics

Cleveland, Ohio, July 28-30, 2008

Prepared under Contracts NNC-05BAZZB and NNC-08JF17T

National Aeronautics and

Space Administration

Glenn Research Center

Cleveland, Ohio 44135 


\section{Acknowledgments}

The work described herein was completed with funding provided by the Science Mission Directorate at NASA Headquarters. The authors thank Dr. Randy Bowman of NASA Glenn Research Center for providing the creep test data and for discussions on technical aspects of creep durability. Also, the authors thank the NASA Glenn technical leadership and management, especially Dick Shaltens, Lanny Thieme, Wayne Wong, and Jeff Schreiber for their inspiring support and assistance.

This report contains preliminary findings, subject to revision as analysis proceeds.

Trade names and trademarks are used in this report for identification only. Their usage does not constitute an official endorsement, either expressed or implied, by the National Aeronautics and Space Administration.

Level of Review: This material has been technically reviewed by technical management.

Available from

NASA Center for Aerospace Information 7115 Standard Drive

Hanover, MD 21076-1320
National Technical Information Service 5285 Port Royal Road Springfield, VA 22161 


\title{
Advanced Stirling Convertor Heater Head Durability and Reliability Quantification
}

\author{
Ashwin R. Shah and Igor Korovaichuk \\ Sest, Inc. \\ Middleburg Heights, Ohio 44130 \\ David L. Krause \\ National Aeronautics and Space Administration \\ Glenn Research Center \\ Cleveland, Ohio 44135 \\ Sreeramesh Kalluri \\ Ohio Aerospace Institute \\ Brook Park, Ohio 44142
}

\begin{abstract}
The National Aeronautics and Space Administration (NASA) has identified the high efficiency Advanced Stirling Radioisotope Generator (ASRG) as a candidate power source for long duration Science missions, such as lunar applications, Mars rovers, and deep space missions, that require reliable design lifetimes of up to 17 years. Resistance to creep deformation of the MarM-247 heater head (HH), a structurally critical component of the ASRG Advanced Stirling Convertor (ASC), under high temperatures (up to $850^{\circ} \mathrm{C}$ ) is a key design driver for durability. Inherent uncertainties in the creep behavior of the thin-walled $\mathrm{HH}$ and the variations in the wall thickness, control temperature, and working gas pressure need to be accounted for in the life and reliability prediction. Due to the availability of very limited test data, assuring life and reliability of the $\mathrm{HH}$ is a challenging task. The NASA Glenn Research Center (GRC) has adopted an integrated approach combining available uniaxial MarM-247 material behavior testing, HH benchmark testing and advanced analysis in order to demonstrate the integrity, life and reliability of the $\mathrm{HH}$ under expected mission conditions. The proposed paper describes analytical aspects of the deterministic and probabilistic approaches and results. The deterministic approach involves development of the creep constitutive model for the MarM-247 (akin to the Oak Ridge National Laboratory master curve model used previously for Inconel 718 (Special Metals Corporation)) and nonlinear finite element analysis to predict the mean life. The probabilistic approach includes evaluation of the effect of design variable uncertainties in material creep behavior, geometry and operating conditions on life and reliability for the expected life. The sensitivity of the uncertainties in the design variables on the $\mathrm{HH}$ reliability is also quantified, and guidelines to improve reliability are discussed.
\end{abstract}

\section{Nomenclature}

$\begin{array}{ll}\text { ASC } & \text { Advanced Stirling Convertor } \\ \text { ASRG } & \text { Advanced Stirling Radioisotope Generator } \\ \text { BOM } & \text { beginning of the mission } \\ \text { CDF } & \text { Cumulative Distribution Function } \\ \text { DOE } & \text { Department of Energy } \\ \text { EOM } & \text { end of the mission } \\ \text { FE } & \text { finite element } \\ \text { FEM } & \text { Finite Element Model } \\ \text { GPS } & \text { general-purpose heat source } \\ \text { GRC } & \text { Glenn Research Center }\end{array}$




$\begin{array}{ll}\text { HH } & \text { heater head } \\ \text { MLE } & \text { Most-likelihood-event } \\ \text { NASA } & \text { National Aeronautics and Space Administration } \\ \text { ORNL } & \text { Oak Ridge National Laboratory } \\ \bar{x} & \left(x_{1}, x_{2}, \ldots, x_{m}\right) \text { - set of } m \text { random variables } \\ G(\bar{x}) & \text { performance or limit-state function } \\ f_{x}(\bar{x}) & \text { joint probability density function of } \bar{x}\end{array}$

\section{Introduction}

The Department of Energy (DOE) is planning to develop the Advanced Stirling Radioisotope Generator (ASRG) for the National Aeronautics and Space Administration (NASA) for potential use on future Science missions, such as lunar applications, Mars rovers, and deep space missions. Lockheed Martin Corporation of Valley Forge, Pennsylvania is the system integrator, under contract to DOE. Sunpower, Inc. of Athens, Ohio is developing the Advanced Stirling Convertor (ASC) to be used in the ASRG under a NASA Research Announcement award with NASA Glenn Research Center (GRC) of Cleveland, Ohio. GRC also provides technology development for the ASC. The ASRG provides substantial efficiency and specific power improvements over radioisotope power systems of heritage designs.

A prime design requirement of the ASRG is to ensure its efficient and reliable performance during the entire mission, up to 17 years long, without inspection, maintenance and repair. Therefore, assessment of reliability of the ASRG is very critical for assured mission success. The ASC is a critical subsystem of the ASRG that converts the thermal energy to electric power. The heater head $(\mathrm{HH})$, a variable-thickness, thin-walled cylindrical pressure vessel, is one of the most critical components of the ASC. The HH hot end conducts heat from a heat collector and general-purpose heat source (GPHS) module of the ASRG and supplies it to the convertor internal heat acceptor.

A traditional $\mathrm{HH}$ design process also involves performing feasible component tests to validate the design in order to assure reliability and durability before long-term structural systems can be accepted for use. However, due to technical and practical limitations, it is not possible to run full-duration, long-term tests that would simulate the actual operational conditions. Additionally, it is difficult to capture the effects of uncertainties in the material behavior, fabrication, manufacturing process, operational load conditions, etc. in a limited number of tests. The current design approach uses computer simulations or virtual experiments, validated with the limited test data, under different design and operating conditions to understand the behavior of components and aid quantification of the long-term behavior and estimate reliability. Computer simulations enable studying the effect of design changes and the impact of variations in critical design variables on component performance in a shorter time at lower cost without performing a full-up test.

The proposed structurally critical cylindrical HH has variable thickness wall sections made from Microcast (small size grains) MarM-247 and is required to function continuously at a maximum temperature of $850^{\circ} \mathrm{C}$ for 17 years. The internally pressurized $\mathrm{HH}$ must not be allowed to distort excessively (or rupture) due to creep at high temperature. This paper investigates the reliability based durability of the preliminary design of the $\mathrm{HH}$ and makes recommendations to improve the design and reliability. The reliability based approach is also outlined and benefits of the investigation are elucidated.

\section{Analysis of Creep Test Data}

Prediction of the creep behavior of the MarM-247 material planned for use in the ASC HH requires test data in order to develop the creep behavior model. An extensive literature survey to collect test data for MarM-247 material was performed, and hardly any data for this alloy with different grain sizes was available in the open literature mainly due to the proprietary nature of the material. Most of the data 
available are related to a single crystal and directionally solidified material which has different creep behavior as compared to the one for the ASC HH. Also, data available from the material handbook were very limited and in the form of the Larson-Miller parameter, which is not useful for the nature of the analysis intended. Therefore, further development and analysis effort for the $\mathrm{HH}$ life reliability relied mostly on the available test data for the MarM-247 from GRC.

Deterministic characterization of the creep behavior requires an appropriate creep law. Different approaches to achieve the objective of developing a master curve to simulate the creep computationally and verify with the test data were pursued. Several approaches, including one similar to that used for Inconel 718 (Special Metals Corporation) by Oak Ridge National Laboratory (ref. 1) (ORNL), were considered in detail. The ORNL temperature-stress dependent, time-to-rupture model in the following form was adopted for the $\mathrm{HH}$ analysis:

$$
\log t_{r}=A_{0}+A_{1} \log \sigma+A_{2}(\log \sigma)^{2}+A_{3}(\log \sigma)^{3}+A_{4} T \log \sigma
$$

with the units used: time, $t$-hours, stress, $\sigma-\mathrm{MPa}$, temperature, $T-\mathrm{K}$; and $A_{0}, A_{1}, A_{2}, A_{3}$, and $A_{4}$ are constants which were determined from the GRC creep test data for Microcast MarM-247 fine grain thick samples.

Characterization of the MarM-247 material using the above creep test data involved the identification of the time to onset of tertiary creep and minimum secondary creep rate. The nature of the data was studied and criteria for primary and secondary creep distinction revealed that the primary creep was insignificant and could be neglected. The time to onset of tertiary creep was determined using the 0.2 percent strain offset. The generalized creep behavior model using the concept of the master curve approach (ref. 1) was developed, and the minimum creep rate, time and strain to onset of tertiary creep and rupture life were computed. The adopted master curve approach involved the following key equations (2) to (4):

$$
e^{*}=\exp \left[\gamma\left(t^{*}-1\right)\right]\left(t^{*}\right) \delta
$$

where $e^{*}\left(=e / e_{s s}\right)$ and $t^{*}\left(=t / t_{s s}\right)$ are normalized creep strain and normalized time, respectively; $e-$ creep strain, $e_{s s}-$ minimum creep strain at onset of tertiary, $t$-time, $t_{s s}$-time to onset of tertiary and $\gamma, \delta$ are material constants. The relationship between minimum creep strain rate and the rupture time is given by

$$
\dot{e}=B t_{r}^{-\alpha}
$$

Here $\dot{e}$ is strain rate, $t_{r}$ is rupture time (hr), and $B$ and $\alpha$ are material constants. Also, the master curve requires the relationship between the time to onset of tertiary and the rupture time as given by

$$
t_{s s}=A t_{r}^{\beta}
$$

where $A$ and $\beta$ are material constants.

The creep behavior model coefficients in the above equations were quantified by performing the nonlinear regression, optimization and statistical analyses of the data for the Microcast MarM-247 fine grain, thick sample, and material creep testing.

A normalized strain (ratio of strain and strain at onset of tertiary creep) and normalized time (ratio of time and time to onset of tertiary creep) for the Microcast MarM-247 fine grain thick sample test data are shown in figure 1. Figure 2 shows the rupture life as a function of temperature and stress.

In order to characterize and develop a reasonable model for the creep behavior of the MarM-247 HH, it is important that the master curve model developed is validated with the test data. A finite element (FE) model simulating the uniaxial specimens with the test loading was developed and creep analysis was performed. The creep model based on the master curve with the coefficients derived for the Microcast MarM-247 fine grain thick samples was used in the simulation. 


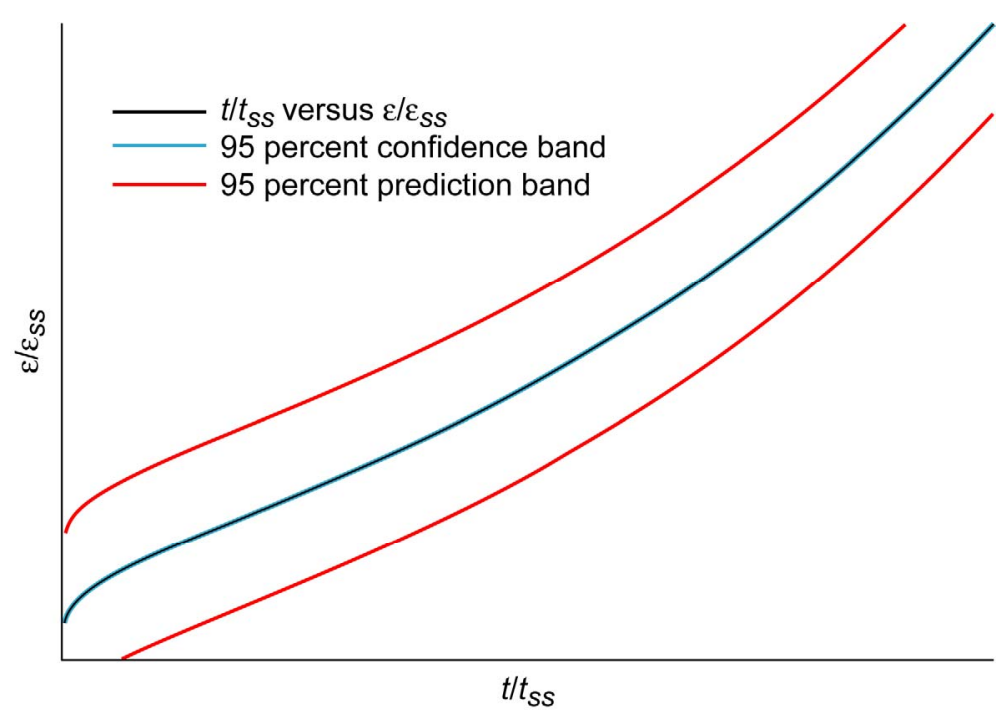

Figure 1.-Normalized time versus normalized creep strain for Microcast MarM-247 fine grain thick sample test data.

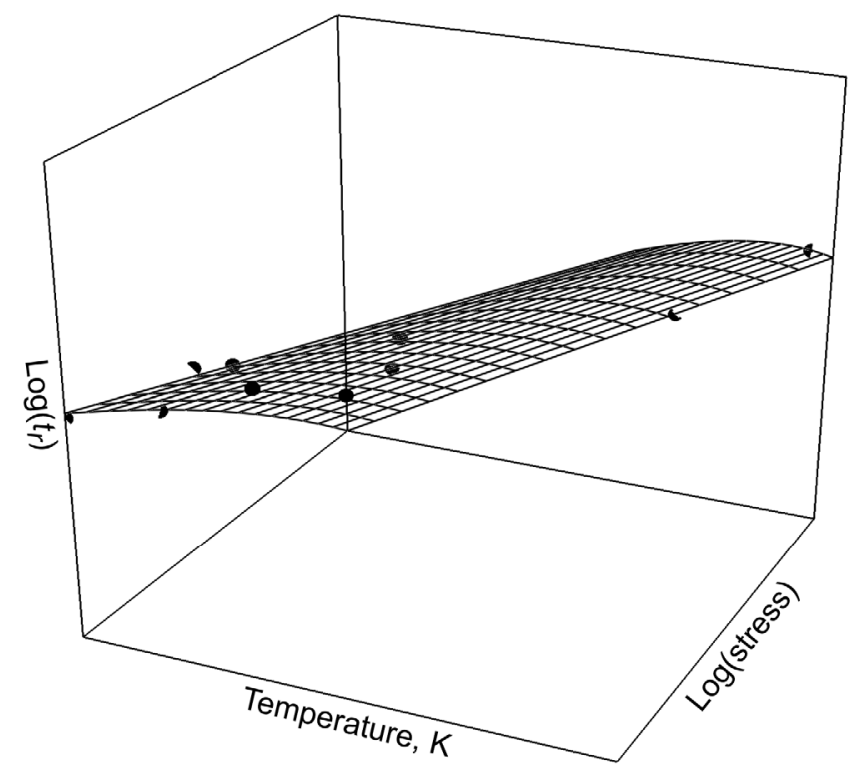

Figure 2.-Microcast MarM-247 fine grain thick sample rupture life as a function of temperature and stress.

Predicted accumulated creep strain was compared with those from the test data at different test temperature and stress conditions. Overall, the developed model works well with most cases for the thick samples, especially under stress and temperature conditions that the HH is likely to experience. It is noted here that the model predictions (with model coefficients based on thick samples test data only) compare fairly well with two thin test samples and significantly under predicts the creep strain for the remaining two tested thin samples. Since the HH life is not set by the life of the thin cylindrical sections, a separate master curve model for the thin material is not required for the current geometry. Variability in the predictions is mainly due to scatter in the creep behavior, which is accounted for in the reliability based life prediction. 


\section{Deterministic Creep Analysis of Heater Head}

Once the creep law has been validated, the next step was to predict the life of the HH. A FE model of the geometry of the $\mathrm{HH}$ was prepared using axisymmetric elements available in the Ansys (SAS IP, Inc.) computer code. Deterministic temperature dependent material properties of MarM-247 were implemented. $850{ }^{\circ} \mathrm{C}$ temperature in the dome region and $90^{\circ} \mathrm{C}$ at the cold end were applied as thermal boundary conditions. An internal pressure load of $3.98 \mathrm{MPa}$ was also applied to the HH. Symmetric boundary conditions at the dome and the fixed boundary conditions at the cold end were applied in the analysis. The constraints due to the integrally-connected heat collector and heat acceptor were not simulated in this analysis, the effects of which are planned for inclusion in future three-dimensional analysis. A nonlinear steady-state heat transfer (conduction) analysis was performed in order to determine the temperature distribution in the $\mathrm{HH}$, followed by a nonlinear creep analysis to obtain time dependent stress and strain distribution in the HH (fig. 3). Several mesh densities were used in order to evaluate the sensitivity of element size on the stresses in the HH. A general observation suggests that the stresses in the dome region, as shown in figure 3 for this earlier $\mathrm{HH}$ design, might be too high for the $\mathrm{HH}$ to provide a functional life of 17 years.

Accumulation of creep strain and the stress relaxation during the mission life under thermal and pressure loads were evaluated in the analysis. Since the creep test data for the GRC MarM-247 showed no significant primary creep, it was omitted in the analysis. Maximum von Mises' stress occurred in the dome region at the start of the mission. The analysis showed that the bending part of the stresses in the $\mathrm{HH}$ relaxed over time. For instance, the maximum stress at the tip of the dome relaxed 35 percent over a period of 17 years as shown in figure 4 .

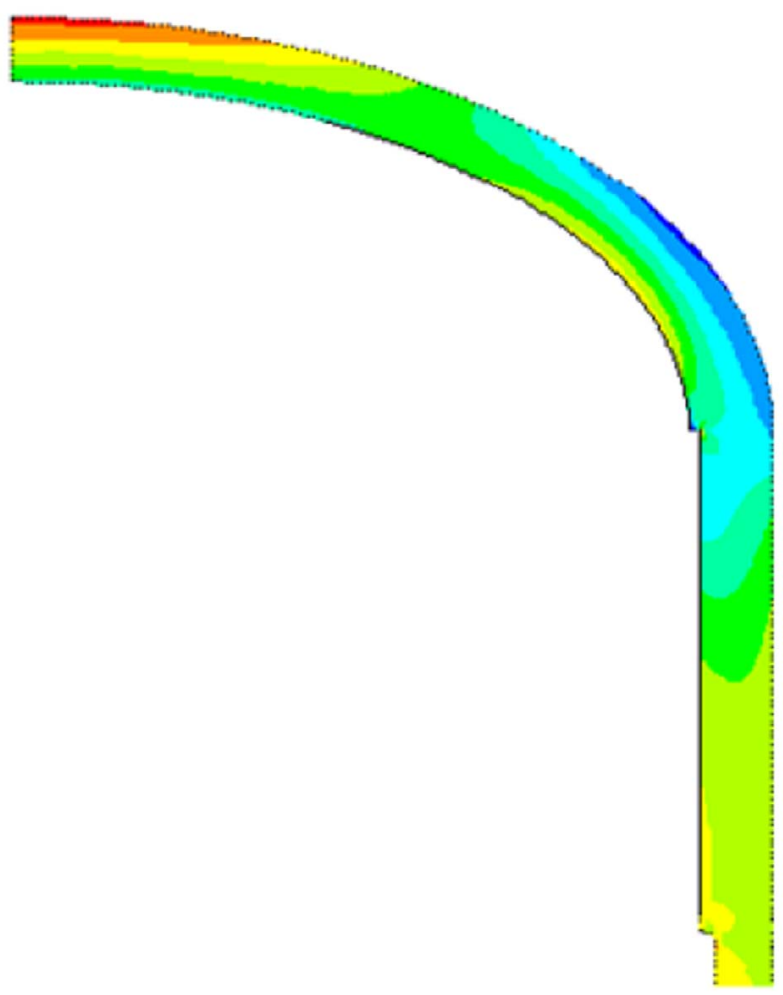

Figure 3.-Contour of equivalent von Mises stresses in the dome region of ASC heater head. 


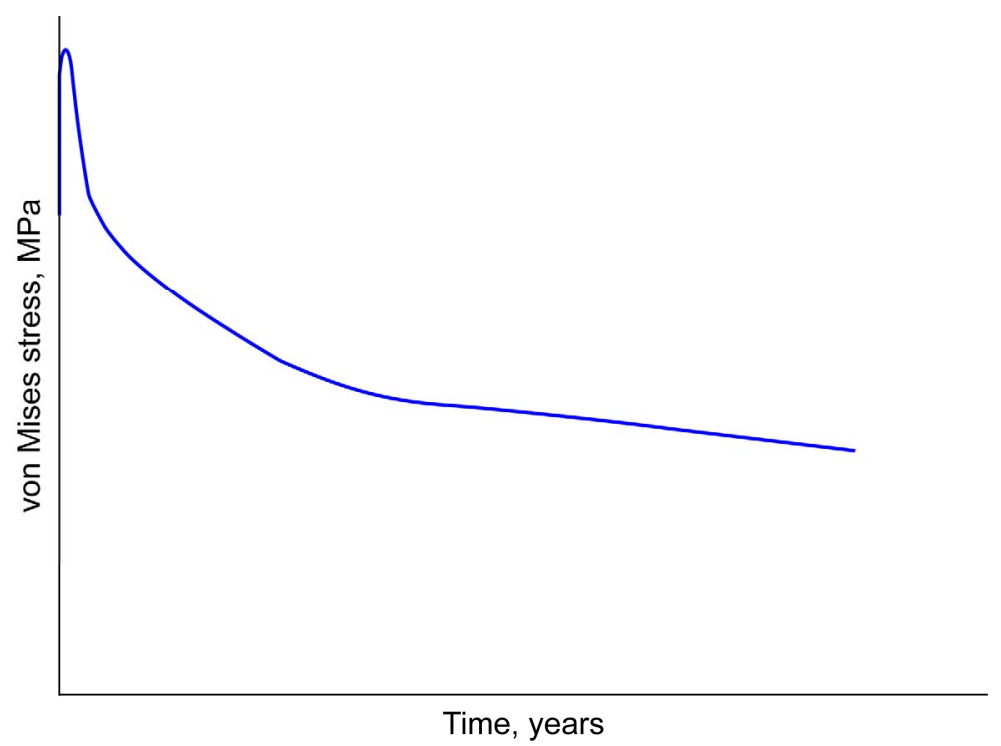

Figure 4.-Predicted stress relaxation in the heater head dome center during the mission.

It is noted that most of the relaxation occurred during the first 5 years. Although the stress reported is at the tip of the dome, the distribution of the stresses across the thickness was studied and is shown in figure 5. It shows that the stress distribution, at the beginning of the mission (BOM), through the dome thickness is comprised of both membrane and bending stresses. It varies from a minimum at the inner surface inside the dome to a maximum at the outer surface of the dome. However, as the creep strain accumulates over a period of time, the stresses relax to mostly membrane in nature at the end of mission (EOM), and the variation through the thickness is minimized at 17 years. It is to be noted that the creep strains do accumulate even though the stresses relax over time. The variation of the creep strain at the end of 17 years is shown in figure 6 .

It is worth noting that the ratio of time to onset of tertiary and the rupture life, $t_{s s} / t_{r}$, becomes higher at lower stresses. Meaning, the life during the tertiary creep zone gets smaller at lower stresses. It has been noted in the analysis that $t_{s s} / t_{r}$ exceeds 0.7 at the stresses observed in the dome. The ASME Boiler and Pressure Vessel Code, Section VIII, Division 2 restricts $t_{s s} / t_{r}$ to a maximum of 0.7 for most class of materials in order to ascertain enough margin in life before failure occurs. Considering the ASME code guidelines, the design criteria based on these guidelines and the maximum tolerable creep strain from the functional requirement for the $\mathrm{HH}$ are recommended herein. It is recommended that the design life criteria be the minimum of 70 percent of the rupture life (ref. 2), the time to onset of tertiary and the life based on the HH tolerable creep strain levels in the component.

Figure 7 shows the equivalent creep strain accumulation as a function of time in the $\mathrm{HH}$, and figure 8 shows the distribution of the equivalent creep strain in the HH. As seen from the figure 8 , the maximum creep strain occurs at the tip of the dome, which in turn governs the life of the HH for this earlier design. It has to be mentioned here that the predicted creep strains in the tapered and thinner section of the HH are based on the master curve creep model parameters identified for the thick sample test data (due to lack of sufficient test data available for thin samples), which may under predict the creep strains in this section. 


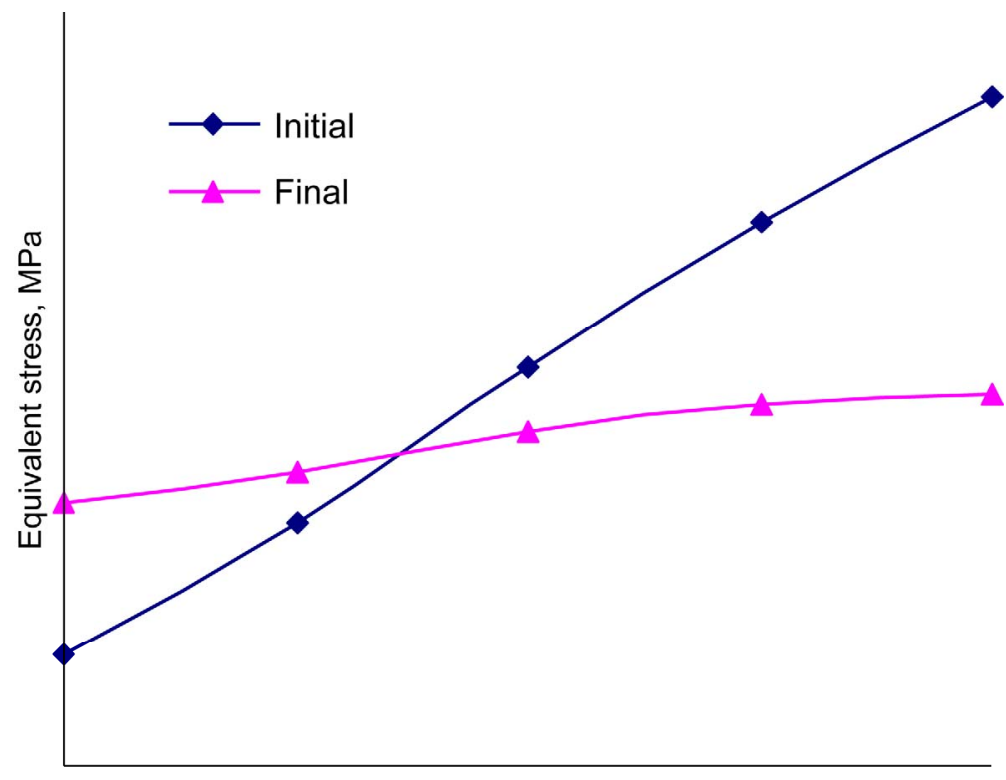

Location, $\mathrm{mm}$

Figure 5.-Variation of von Mises stresses through the thickness in the beginning and at 17 years at tip of dome.

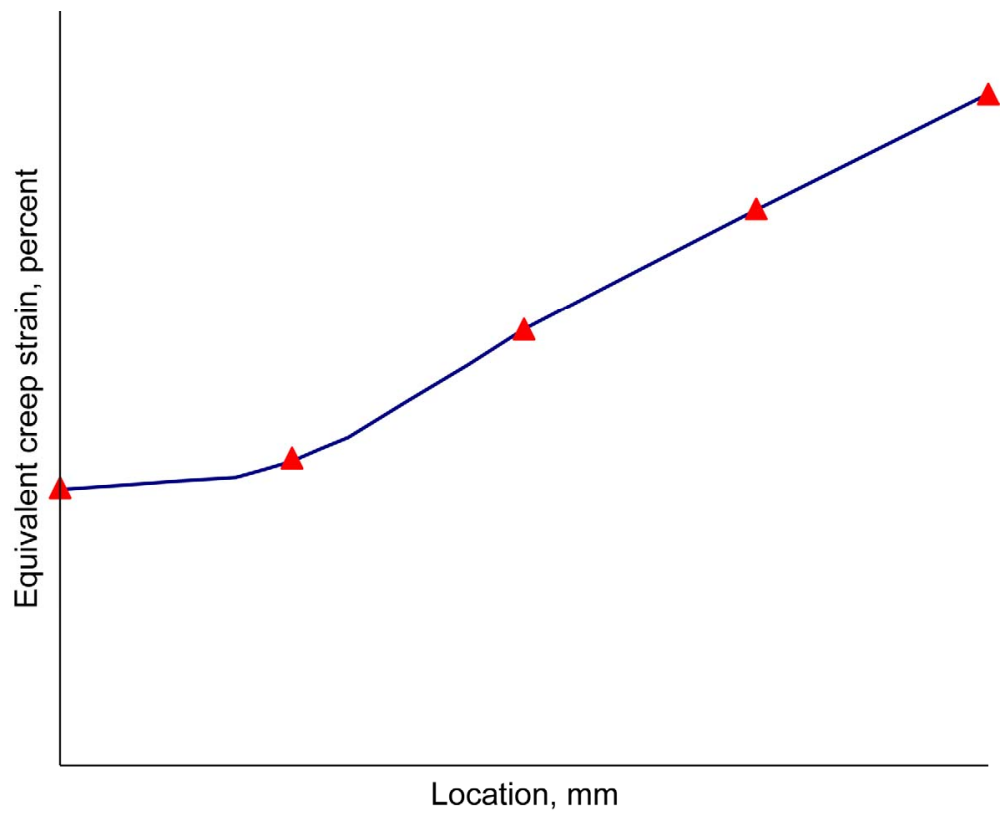

Figure 6.-Variation of von Mises creep strains through the thickness at 17 years at tip of dome. 


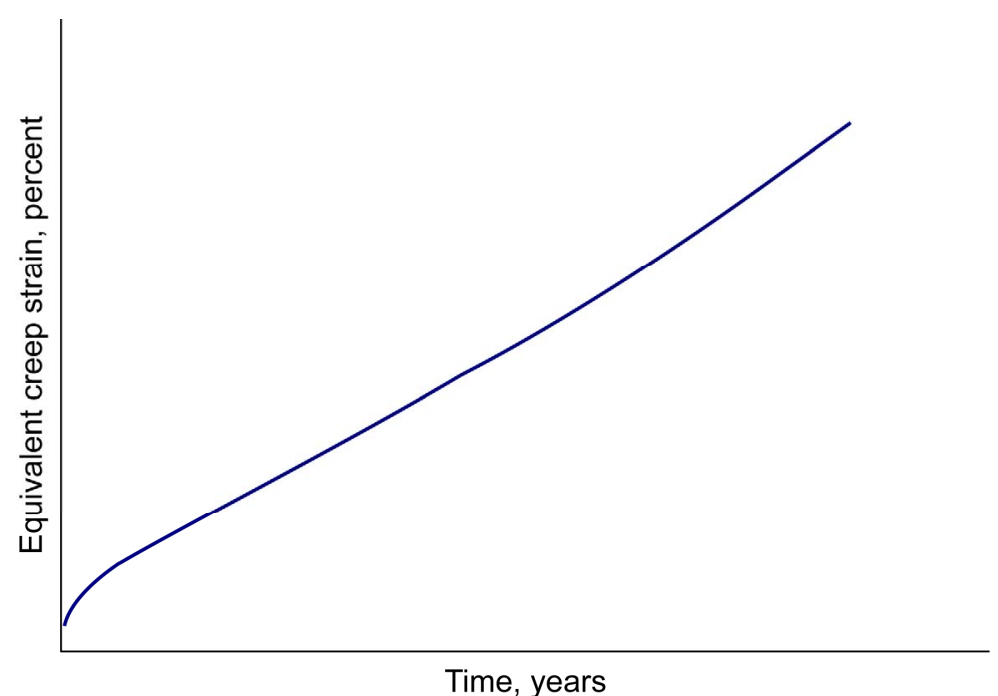

Figure 7.-Equivalent creep strain at tip of dome during the mission.

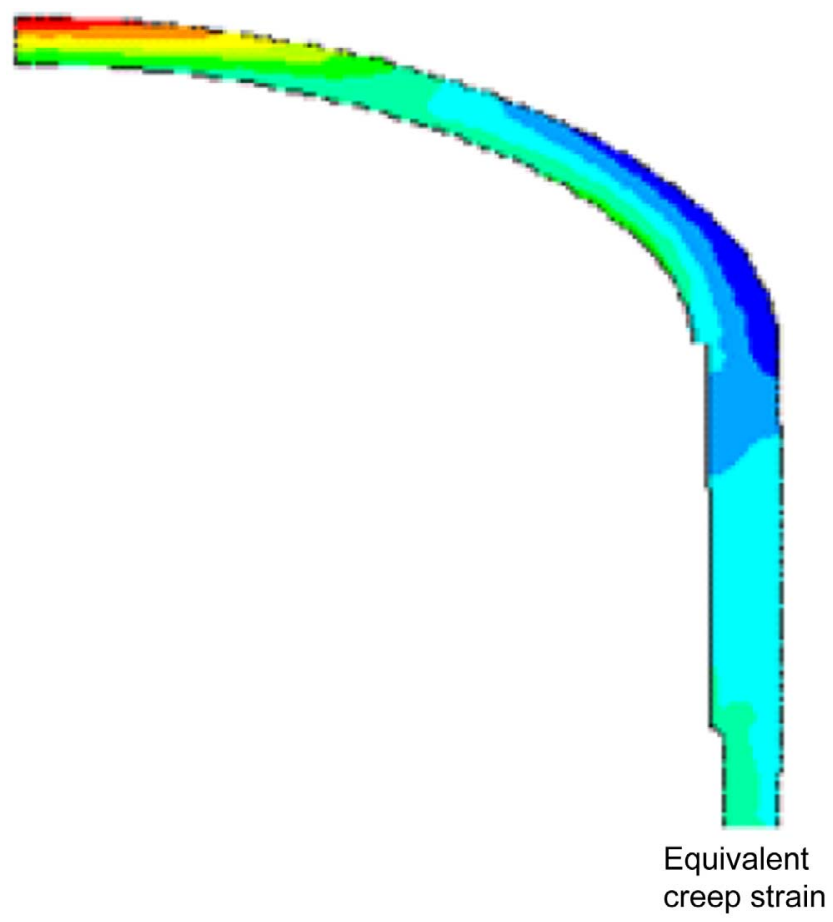

Figure 8.-Distribution of equivalent creep strain in the heater head at 17 years. 


\section{Reliability Based Creep Analysis of Heater Head}

Reliable durability and required functional performance, without inspection, maintenance and repair, must be demonstrated before long-term structural systems can be accepted for use. The reliability assessment involves capturing the effect of uncertainties in the design variables relating fabrication process, geometry, material behavior, loading and mission environment conditions. Due to technical limitations, in addition to time and cost constraints, it is not possible to run full-duration, long-term tests that simulate the actual operational conditions, and it is difficult to capture the effects of design variable uncertainties in a limited number of tests. Therefore, the use of computer simulations or virtual experiments, validated with limited test data, is a viable approach to understand the behavior of components, aid quantification of the long-term behavior and estimate reliability. It also enables engineers to quantify the impact of variations in critical design variables on component reliability.

In order to quantify the reliability of the ASC $\mathrm{HH}$, a probabilistic life analysis that includes the effect of uncertainties in the geometry, pressure and temperature has been performed. Uncertainty in the geometry is selected such that the bounds on the fabrication tolerances relate to \pm 3 standard deviations. The uncertainty in the pressure is assumed such that the convertor pressure amplitude of 10 percent corresponds to \pm 3 standard deviations. The analysis does not account for the variation in the hot-end temperature, since it is assumed that the temperature is maintained by the controller and temperature effects on reliability will be accounted for in the controller reliability analysis. Quantifying uncertainties in the material creep behavior is difficult due to the availability of limited test data. Additionally, there are no more than two tests performed for a given cast or grain size at a given stress and temperature condition.

Hence, quantification of uncertainties in a rational manner using this data is very difficult. Several different approaches and methodologies were adopted to quantify the uncertainties in the material creep behavior; however, important related aspects are described and only the final results are presented in the report. In order to completely describe and quantify uncertainties in the material behavior involves quantifying the uncertainties in all the coefficients of the master curve model (eqs. (1) to (4)). Also, it should be noted that these coefficients are correlated in a probabilistic sense. A large amount of test data is needed to quantify uncertainties and cross covariance matrices among these coefficients. In order to circumvent the necessity of this large amount of test data, an engineering approach has been adopted based on the assumption that all these coefficients are fully correlated and all the uncertainties can be lumped into only one constant $A_{0}$ in equation (1), which is more or less reflective of the material behavior.

Several probabilistic approaches and methodologies were adopted to characterize probabilistic distributions and scatter in the creep behavior of MarM-247 material. The method of most-likelihoodevent (MLE) combined with the least squares approach within 95 percent confidence bounds has been used to quantify uncertainties in the material behavior. Several statistical goodness-of-fit tests, such as Anderson-Darling, Standard residuals, and Cox-Snell, were applied to validate the quantified parameters. Analysis of the test data suggest that the rupture life is log normally distributed, figure 9, and the scatter ( $\pm 3 \sigma$ variation) is up to 280 percent within the magnitudes of temperature and stress tested. The scatter in the time to onset of tertiary creep, figure 10 , also has similar scatter (300 percent), whereas the scatter in the strain to onset of tertiary creep is about 98 percent.

Regardless, the scatter in all variables is considerably large. Therefore, a reliability assessment of components made of MarM-247, with large scatter in creep durability, is critical. The scatter in the constant, $A_{0}$, related to material behavior uncertainties is 1.72 percent. Thus, it is obvious how sensitive this constant is to the rupture life. A small variation in the constant can cause a large variation in the creep durability. The uncertainties and distributions used for each variable are listed in table 1 . The magnitude of these uncertainties could change if more realistic information becomes available, such as further material test data, actual mission profiles, etc. 


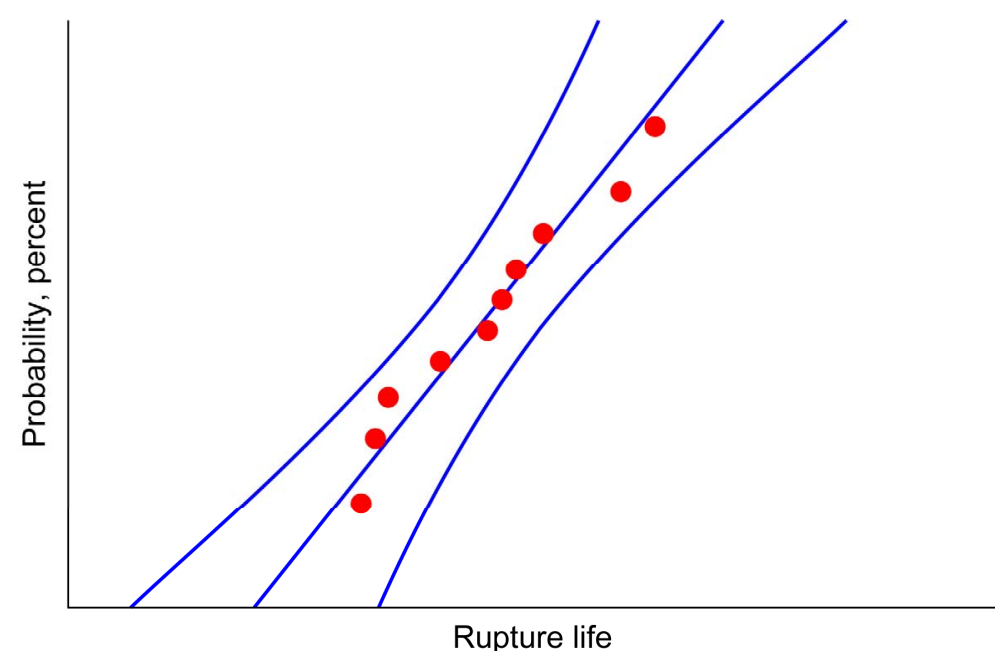

Figure 9.-Probabilistic characterizations of Microcast MarM-247 rupture life.

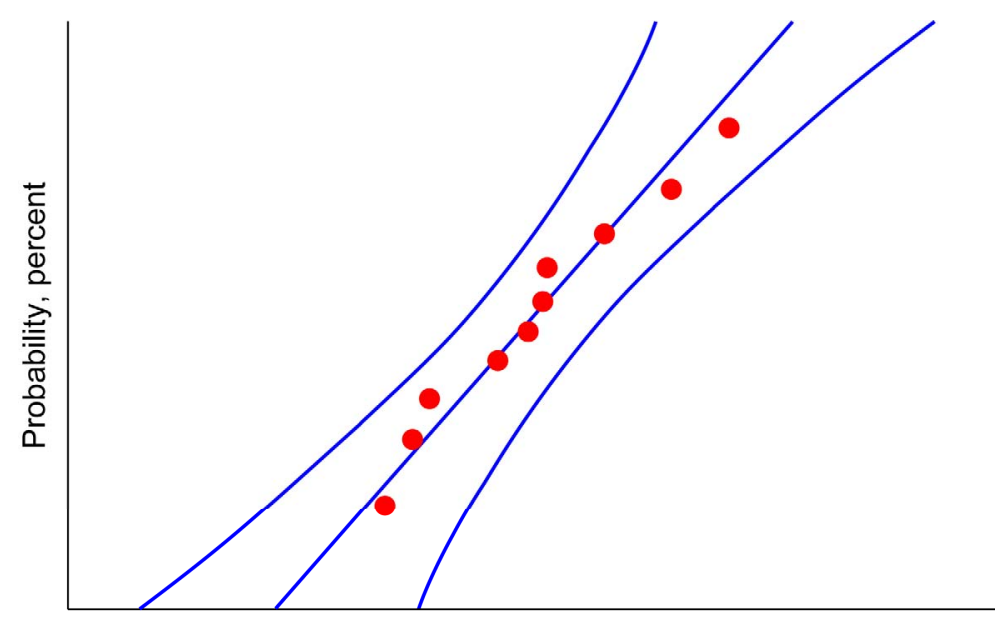

Time to onset of tertiary creep

Figure 10.—Probabilistic characterization of the Microcast MarM-247 time to onset of tertiary creep.

TABLE 1.-UNCERTAINTIES IN THE HEATER HEAD DESIGN VARIABLES

\begin{tabular}{|l|c|c|c|c|}
\hline \multicolumn{1}{|c|}{ Variable } & Mean & $\begin{array}{l}\text { Standard } \\
\text { deviation }\end{array}$ & $\begin{array}{c}\text { Coefficient of variation, } \\
\text { (Percent) }\end{array}$ & Distribution \\
\hline $\begin{array}{l}\text { Pressures, } \\
(\mathrm{MPa})\end{array}$ & ---- & --- & 0.57 & Lognormal \\
\hline $\begin{array}{l}\text { Critical wall thickness, } \\
(\mathrm{mm})\end{array}$ & ---- & ---- & 0.555 & Weibull \\
\hline $\begin{array}{l}\text { Material constant, } \\
A_{0}\end{array}$ & ---- & ---- & 0.574 & Normal \\
\hline
\end{tabular}


As discussed earlier the recommended design life criteria should be based on the level of strain as well as the time to onset of tertiary creep. The probabilistic life analysis at different life times has been performed to quantify the creep strain for different reliability levels. The probability distribution function for the creep strain after 50,000 $\mathrm{hr}(5.71 \mathrm{yr}), 100,000 \mathrm{hr}(11.4 \mathrm{yr})$, and 150,000 hr (17.2 yr) is depicted in figure 11 .

Results provide a creep strain limit for a life of 17 years with assured reliability of 0.999 . It is possible that a large creep strain over the limit, if any, may fall in the tertiary creep zone or may have reached the rupture life, which can be verified by examining the creep ductility of the material and performing the failure analysis. Additionally, the sensitivity analysis, as shown in figures 12 and 13, suggests that the creep strain reliability is most sensitive to uncertainties in the material behavior (as expected due to the scatter being large). Sensitivity is defined as the level of significance to the reliability, on a scale of 0 to 1 ( 0 being the least and 1 being the most), of the uncertainties in a given variable.

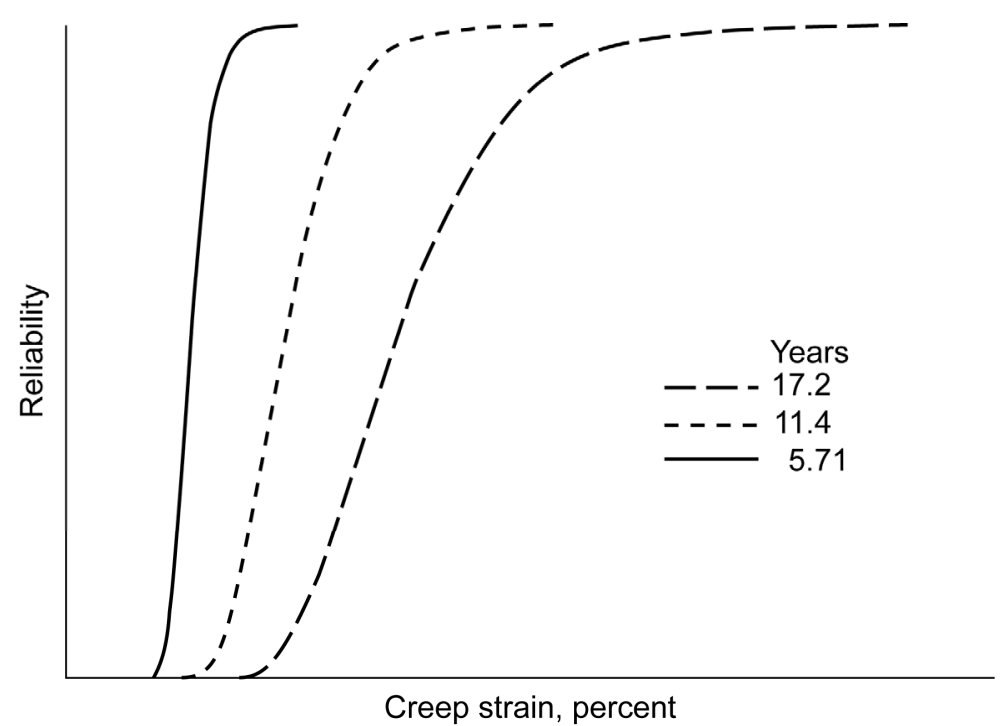

Figure 11.-Probability of heater head creep strain at various life spans.

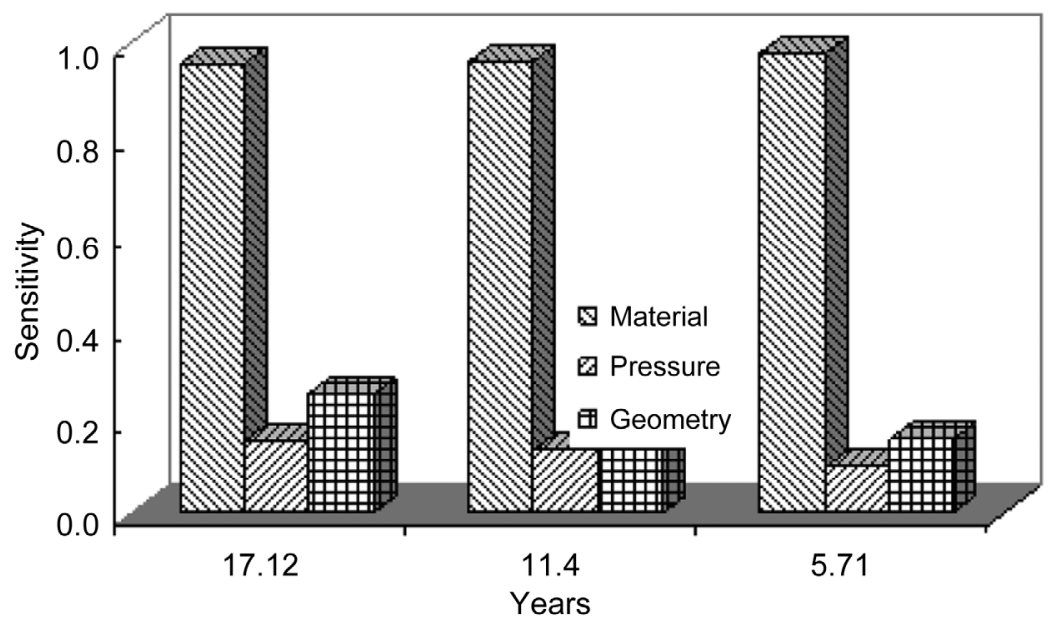

Figure 12.-Sensitivity factors of random variables to maximum creep strain for 0.01 probability. 


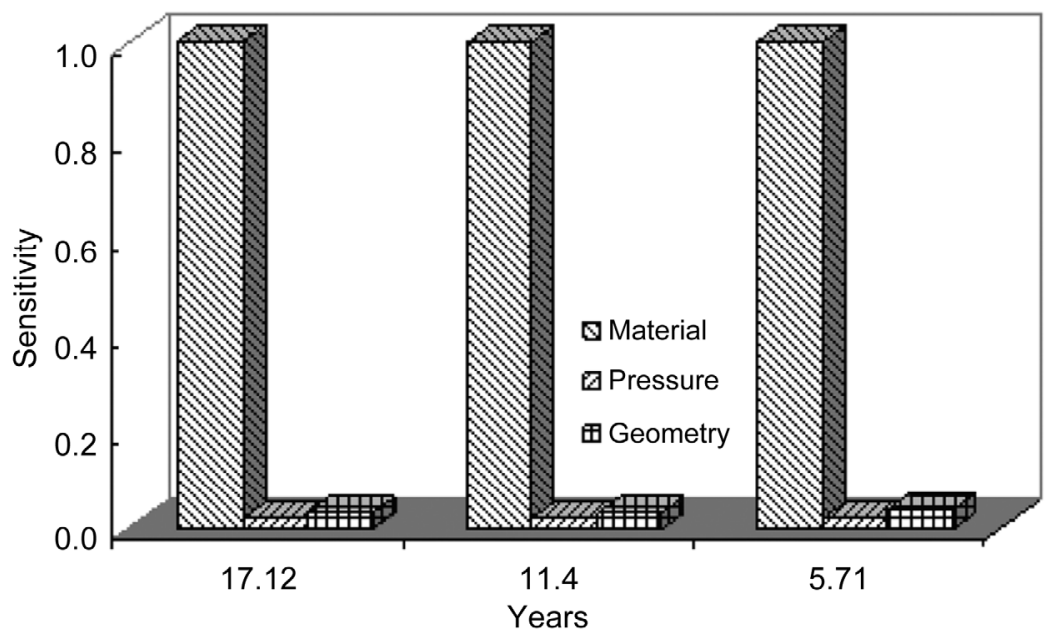

Figure 13.-Sensitivity factors of random variables to maximum creep strain for 0.999 probability.

It is also seen from figures 12 and 13 that the sensitivity of uncertainties to the material creep behavior becomes more dominant as the reliability requirement is increased. Therefore, in order to improve the reliability of the $\mathrm{HH}$, the uncertainties in the material creep behavior should be reduced. This can be achieved by imposing well controlled material processing, heat treatment, quality control and $\mathrm{HH}$ processing.

Since the GRC material characterization is based on limited test data, the reported analysis could be refined with the availability of more test data which may show reduced scatter in the material creep behavior and improved reliability of the ASC HH.

\section{Validation of ASC Heater Head Durability Analysis}

The reliability analysis performed and described in this paper will be validated with $\mathrm{HH}$ structural benchmark testing (ref. 3). The validation process verifies the applicability of the creep model developed based on the uni-axial test data and applied to the biaxial state of stress in the $\mathrm{HH}$, as well as the overall methodology used in the presented analysis. ASC HH benchmark test data are not yet available; however, the methodology for validation is described below. It consists of the following steps:

(1) Model the accepted geometry of the $\mathrm{HH}$ and develop a finite element model;

(2) Apply thermal profile used in the benchmark test with variation in the test temperatures modeled as $3-\sigma$ variation;

(3) Apply actual pressure used in the benchmark test with variation in the test pressure modeled as $3-\sigma$ variation;

(4) Use the master curve creep model developed in this report for Microcast MarM247 fine grain material;

(5) Perform the nonlinear finite element creep durability analysis of the benchmark $\mathrm{HH}$;

(6) Compare the cumulative creep strain measured with the computed strain and verify if it falls within the calculated $3-\sigma$ bounds. Analysis is considered validated if the computed strain falls within the $3-\sigma$ bound. If it does not, investigate the model and fine tune the analysis to better reflect the experimental setup with instrumentation variation, etc. 


\section{Conclusions}

Analysis of the Microcast MarM-247 fine grain uniaxial test data was performed to develop the master curve based creep model and quantify the uncertainties in the material creep behavior required to perform a reliability-based life assessment of the ASC HH. The master curve based model was validated by comparing with the results of a nonlinear finite element analysis of the uniaxial test specimens. This comparison showed very good agreement between the test data and predicted analysis results.

Deterministic nonlinear finite element creep analysis of an earlier version of the ASC HH was performed to predict the cumulative creep strain in 17 years of mission life. This analysis shows that the maximum cumulative creep-strain occurs at the tip of dome, and the maximum average creep strain through thickness also occurs at the same location. Uncertainties in the geometry, material properties (long-term creep behavior), and operating conditions (pressure) were included in the quantification of the life and reliability. A probability integration of the uncertainties in the input design variables and their effect on material creep was performed to quantify the reliability-based creep strains and sensitivity of the design variables. The analysis showed the maximum creep strains allowed at the tip of the dome for 17 years of life and 99.9 and 99.99 percent reliability. The quantified sensitivities clearly show that the creep strain and reliability are most sensitive to the uncertainties in the material properties (creep behavior), followed by geometry and pressure. In order to assure or improve the reliability, uncertainties in the material properties need to be controlled.

It is to be noted here that the creep durability and reliability predictions and material characterizations are based on a limited number of NASA GRC tests on the HH material and may change with additional test data. Factoring in available test data from structural benchmark testing should also enhance the confidence in the reliability results.

\section{References}

1. Brinkman, C.R., Booker, M.K., and Ding, J.L., "Creep and Creep-Rupture Behavior of Alloy 718," in Superalloys 718, 625, and Various Derivatives, edited by E.A. Loria, The Minerals, Metals \& Materials Society, Warrendale, PA, 1991, pp. 519-536.

2. Mino, Kazuaki, et al., "Residual Life Prediction of Turbine Blades of Aeroderivative Gas Turbines," Advanced Engineering Materials, 2001, 3, no. 11.

3. Krause, D.L., Kalluri, S., Bowman, R.R., and Shah, A.R., "Structural Benchmark Creep Testing for the Advanced Stirling Convertor Heater Head," Proceedings of the 6th International Energy Conversion Engineering Conference (IECEC), AIAA Conference Proceedings 2008-5772, Reston, VA, to be published 2008 . 


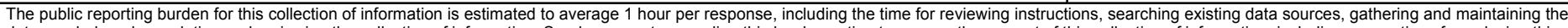

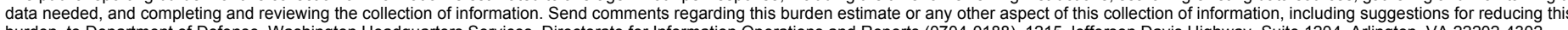

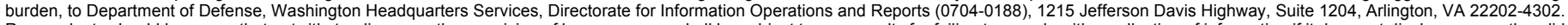

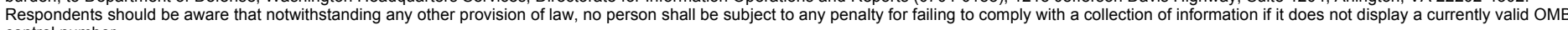

control number.
PLEASE DO NOT RETURN YOUR FORM TO THE ABOVE ADDRESS.

\begin{tabular}{l|l} 
1. REPORT DATE $(D D-M M-Y Y Y Y)$ & 2. REPORT TYPE
\end{tabular}

01-11-2008

Technical Memorandum

3. DATES COVERED (From - To)

4. TITLE AND SUBTITLE

January 2008-July 2008

Advanced Stirling Convertor Heater Head Durability and Reliability Quantification

5a. CONTRACT NUMBER

NNC-05BAZZB; NNC-08JF17T

5b. GRANT NUMBER

5c. PROGRAM ELEMENT NUMBER

6. AUTHOR(S)

Shah, Ashwin, R.; Korovaichuk, Igor; Krause, David, L.; Kalluri, Sreeramesh

5d. PROJECT NUMBER

5e. TASK NUMBER

5f. WORK UNIT NUMBER

WBS 138494.04.01.01

\section{PERFORMING ORGANIZATION NAME(S) AND ADDRESS(ES}

National Aeronautics and Space Administration

8. PERFORMING ORGANIZATION

REPORT NUMBER

John H. Glenn Research Center at Lewis Field

E-16652

Cleveland, Ohio 44135-3191

\section{SPONSORING/MONITORING AGENCY NAME(S) AND ADDRESS(ES)}

National Aeronautics and Space Administration

Washington, DC 20546-0001

\section{SPONSORING/MONITORS ACRONYM(S)}

NASA; AIAA

11. SPONSORING/MONITORING REPORT NUMBER

NASA/TM-2008-215449; AIAA-20085772

\section{DISTRIBUTION/AVAILABILITY STATEMENT}

Unclassified-Unlimited

Subject Categories: 26 and 38

Available electronically at http://gltrs.grc.nasa.gov

This publication is available from the NASA Center for AeroSpace Information, 301-621-0390

\section{SUPPLEMENTARY NOTES}

\section{ABSTRACT}

The National Aeronautics and Space Administration (NASA) has identified the high efficiency Advanced Stirling Radioisotope Generator (ASRG) as a candidate power source for long duration Science missions, such as lunar applications, Mars rovers, and deep space missions, that require reliable design lifetimes of up to 17 years. Resistance to creep deformation of the MarM-247 heater head (HH), a structurally critical component of the ASRG Advanced Stirling Convertor (ASC), under high temperatures (up to $850{ }^{\circ} \mathrm{C}$ ) is a key design driver for durability. Inherent uncertainties in the creep behavior of the thin-walled HH and the variations in the wall thickness, control temperature, and working gas pressure need to be accounted for in the life and reliability prediction. Due to the availability of very limited test data, assuring life and reliability of the $\mathrm{HH}$ is a challenging task. The NASA Glenn Research Center (GRC) has adopted an integrated approach combining available uniaxial MarM-247 material behavior testing, $\mathrm{HH}$ benchmark testing and advanced analysis in order to demonstrate the integrity, life and reliability of the $\mathrm{HH}$ under expected mission conditions. The proposed paper describes analytical aspects of the deterministic and probabilistic approaches and results. The deterministic approach involves development of the creep constitutive model for the MarM-247 (akin to the Oak Ridge National Laboratory master curve model used previously for Inconel 718 (Special Metals Corporation)) and nonlinear finite element analysis to predict the mean life. The probabilistic approach includes evaluation of the effect of design variable uncertainties in material creep behavior, geometry and operating conditions on life and reliability for the expected life. The sensitivity of the uncertainties in the design variables on the $\mathrm{HH}$ reliability is also quantified, and guidelines to improve reliability are discussed.

\section{SUBJECT TERMS}

Stirling cycle; Mechanical properties; Creep rupture strength; Steady state creep; Strain rate; Deformation; Life (Durability); Nickel alloys; Durability; Reliability; Probability theory

\begin{tabular}{|l|l|l|l|l|l|}
\hline \multicolumn{2}{|l|}{ 16. SECURITY CLASSIFICATION OF: } & $\begin{array}{l}\text { 17. LIMITATION OF } \\
\text { ABSTRACT }\end{array}$ & $\begin{array}{l}\text { 18. NUMBER } \\
\text { OF } \\
\text { PAGES }\end{array}$ & $\begin{array}{l}\text { 19a. NAME OF RESPONSIBLE PERSON } \\
\text { STI Help Desk (email:help@sti.nasa.gov) }\end{array}$ \\
\cline { 1 - 2 } $\begin{array}{l}\text { a. REPORT } \\
\text { U }\end{array}$ & $\begin{array}{l}\text { b. ABSTRACT } \\
\text { U }\end{array}$ & $\begin{array}{l}\text { c. THIS } \\
\text { PAGE } \\
\text { U }\end{array}$ & UU & 19 & $\begin{array}{l}\text { 19b. TELEPHONE NUMBER (include area code) } \\
\text { 301-621-0390 }\end{array}$ \\
& & &
\end{tabular}



